\title{
Moisture Absorption and Desorption Predictions for Plastic Ball Grid Array Packages
}

\author{
Jesse E. Galloway and Barry M. Miles
}

\begin{abstract}
Plastic electronic packages are known to absorb moisture when exposed to humid ambient conditions during storage in tape and reel in the factory. Reliability becomes a concern when packages are exposed to a humid environment for a prolonged time and then processed through a reflow oven. Thermo-mechanical and moisture induced interfacial stresses generated between the die attach and die may lead to die delamination and package cracking. Current package level moisture evaluation methods are based on experimental weight gain measurements and visual inspection after reflow for cracking or delamination. This study presents a finite element analysis (FEA) simulation of the moisture weight gain or loss in plastic ball grid array (PBGA) packages as a function of time, including the effects of package geometry and material selection. Experimental weight gain and bake-out data for a 68 I/O PBGA package are shown to closely match FEA model predictions. Diffusivity and solubility property data for common packaging materials are given as a function of temperature from 23 to $210{ }^{\circ} \mathrm{C}$. Solder pot dip tests performed at $230{ }^{\circ} \mathrm{C}$ indicate that popcorn failures result when the moisture concentration in the die attach region exceeds 0.0048 $\mathrm{g} / \mathrm{cm}^{3}$ for the specific package tested.
\end{abstract}

Index Terms - Diffusion, finite element analysis simulations, moisture, plastic ball grid array, popcorn.

\section{INTRODUCTION}

$\mathbf{N}$ UMEROUS studies reported in the literature document the damaging effect caused when plastic packages are stored in a noncontrolled humidity environment. When water vapor, present in the factory environment, is absorbed through the package exterior, it condenses in micropores in the substrate, solder mask, die attach materials, and along interfaces, particularly in the die attach-die flag and die attach-die interfaces. During reflow, condensed moisture vaporizes, creating an over-pressure condition. Under severe conditions, the combined thermomechanical and moisture induced stresses force the substrate outward away from the die, creating a stress singularity at the edge of the die-overmold or die attach-BT epoxy interface. As a result, a crack forms that may propagate laterally outwards. When the crack reaches the package exterior, high pressure water vapor is suddenly released, producing an audible popping sound. Fig. 1 shows an example of a "popcorn" failure as evidenced by the cracked package. The die is completely delaminated from the die attach. A crack initiated at the corner of the die and propagated through the die attach fillet into the substrate.

Manuscript received October 1, 1996; revised March 1, 1997.

The authors are with the Advanced Manufacturing Technology Center, Motorola, Plantation, FL 33322 USA (e-mail: ejg010@email.mot.com; ejg005@email.mot.com).

Publisher Item Identifier S 1070-9886(97)06041-1.

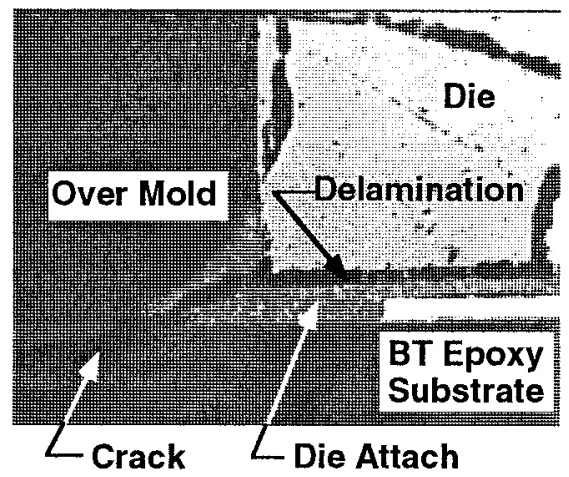

Fig. 1. PBGA popcorn failure showing package cracking and delamination.

Popcorning may break wire bonds or degrade long term reliability by the presence of a crack, which provides a path for corrosive material to enter the package. Also, a degradation in the thermal performance results when the die delaminates, particularly so for high power devices.

Considerable resources must be committed to experimentally validate new packaging processes, designs, or materials using the JEDEC standard [1]. Many of the moisture studies found in the literature focus on JEDEC type qualification tests showing a relation between package weight gain and package cracking or delamination [2]. However, experimental results measured for one specific package design with certain material properties, geometry, and process conditions are not easily generalized to predict popcorn failures for new designs or conditions. To predict popcorn failures, the stress state must be known at the location where the failure initiates. For PBGA packages, failures typically initiate by a delamination of the die-die attach interface followed by the propagation of a crack through the overmold or substrate. In order to predict the moisture induced stress state, the local moisture concentration must be known in the die attach region. Moisture transport models developed for plastic encapsulated packages are readily available [3] but cannot be easily extended to account for multilayer materials used to fabricate PBGA's.

The objectives of this study are as follows. First, measure the moisture diffusivity and solubility as a function of temperature for various PBGA packaging materials. Second, develop a method to predict moisture transport through a multilayer package having different properties in each layer. Third, develop a FEA method for predicting the moisture weight gain and local concentration for a specific PBGA package, including three-dimensional (3-D) geometry effects such as pad metallization and internal vias. Fourth, determine 
the critical moisture concentration that produces a package failure during a solder dip test.

\section{Moisture Modeling}

Moisture absorption and desorption properties of PBGA packaging materials are determined by measuring the weight gain or loss as a function of time, and fitting the response to an analytical model. A 3-D diffusion model is presented to provide physical insight into the moisture absorption and desorption processes. Experimental data are presented to validate the proposed diffusion model and to provide numerical values for the diffusivity and solubility as a function of temperature.

\section{A. Diffusivity Measurements}

PBGA materials transport moisture primarily by diffusion, although secondary effects such as surface tension and pressure driven flows may also contribute. Moisture transport strictly by diffusion is modeled using the standard transient diffusion

$$
\frac{\partial^{2} C}{\partial x^{2}}+\frac{\partial^{2} C}{\partial y^{2}}+\frac{\partial^{2} C}{\partial z^{2}}=\frac{1}{\alpha} \frac{\partial C}{\partial t}
$$

where $C$ is the local concentration $\left(\mathrm{g} / \mathrm{cm}^{3}\right), x, y, z$ are coordinates $(\mathrm{cm}), \alpha$ is the diffusivity $\left(\mathrm{cm}^{2} / \mathrm{s}\right)$, and $t$ is the time (s).

Secondary moisture transport mechanisms are ignored in developing (1). Later, this assumption will be verified. Equation (1) is solved using standard separation of variable techniques (Gebhart [4]), yielding an expression for the local moisture concentration as a function of time, position, and diffusivity. Local concentration data are unavailable but the total weight gain is easily measured. Hence, an analytical expression for the total weight gain as a function of time is obtained by integrating the local concentration over the volume of the rectangular block sample

$$
\begin{aligned}
& \frac{m(t)}{m_{\text {sat }}}= 1-\frac{512}{\pi^{6}} \sum_{l=0}^{4} \sum_{m=0}^{4} \sum_{n=0}^{4} \frac{\exp \left(\frac{-\alpha t}{L_{\text {eqv }}^{2}}\right)}{(2 l+1)^{2}(2 m+1)^{2}(2 n+1)^{2}} \\
& L_{\text {eqv }}^{2}=\left\{\left[\frac{(2 l+1) \pi}{x_{o}}\right]^{2}+\left[\frac{(2 m+1) \pi}{y_{o}}\right]^{2}\right. \\
&\left.+\left[\frac{(2 n+1) \pi}{z_{o}}\right]^{2}\right\}^{-1}
\end{aligned}
$$

where $m(t)$ is the instantaneous mass of the sample, $m_{\text {sat }}$ is the saturated mass, $L_{\text {eqv }}$ is an equivalent length scale, $x_{o}, y_{o}, z_{o}$ are the length, width, and thickness dimensions, respectively. Equation (2) converges within 1 to $2 \%$ for the sample dimensions reported here when four terms are included in each summation.

Samples were prepared by precision-grinding the length and width dimensions, $x_{0}$ and $y_{o}$, to $9.53 \pm 0.013 \mathrm{~mm}$ and the thickness dimension, $z_{0}$, from 0.155 to $1.05 \pm 0.003$ $\mathrm{mm}$. Moisture diffusivity and solubility data were gathered by periodically weighing samples soaked in a humidity chamber controlled to an accuracy of $\pm 1{ }^{\circ} \mathrm{C}$ and $\pm 1 \%$ relative humidity (RH). A Sartorius analytical balance, having an accuracy of
TABLE I

EXPERIMENTAL Absorption AND Desorption Test Conditions

\begin{tabular}{c|c|c}
\hline Test & $\begin{array}{c}\text { Dry Bulb } \\
\text { Temperature } \\
\left({ }^{\circ} \mathrm{C}\right)\end{array}$ & $\begin{array}{c}\text { Relativc } \\
\text { Humidity } \\
(\%)\end{array}$ \\
\hline Absorption & 23 & 50 \\
\hline Absorption & 30 & $30,60,85$ \\
\hline Absorption & 50 & 85 \\
\hline Absorption & 85 & $30,50,60,85$ \\
\hline Desorption & 85 & 3 \\
\hline Desorption & 110 & 0 \\
\hline Desorption & 130 & 0 \\
\hline Desorption & 150 & 0 \\
\hline Desorption & 180 & 0 \\
\hline Desorption & 210 & 0 \\
\hline
\end{tabular}

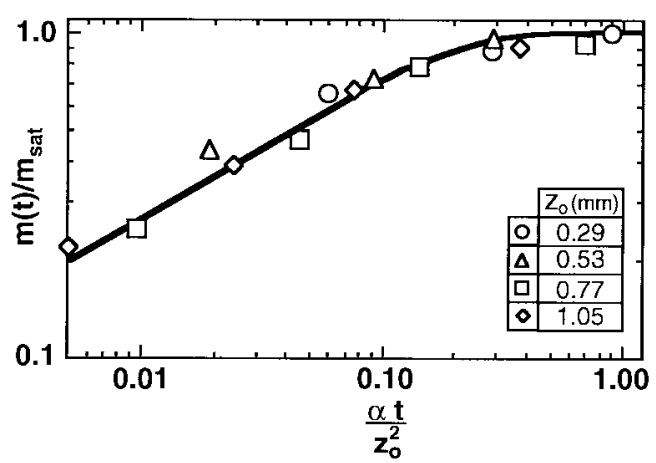

Fig. 2. Experimental weight gain data compared to 3-D analytical model predictions for overmold at $50{ }^{\circ} \mathrm{C} / 85 \% \mathrm{RH}$.

$\pm 0.01 \mathrm{mg}$ was used to weigh samples. The samples were first dried in an oven at $110{ }^{\circ} \mathrm{C}$ for at least $24 \mathrm{~h}$, and then weighed to determine the dry weight. The samples were then placed in vented containers and inserted into the humidity chamber through a side port, rather than disturbing the test conditions by opening and closing the chamber door. Samples were periodically removed from the humidity chamber and weighed. The ambient moisture conditions were set by specifying the dry bulb temperature and the relative humidity. Desorption studies were conducted using data gathered with a thermogravimetric analysis (TGA) instrument. Table I lists the ambient conditions tested during absorption and desorption studies.

Diffusivity constants were determined by minimizing the difference between the model predictions given by (2) and the experimental weight gain versus time data.

Fig. 2 shows a comparison between the experimental and predicted weight gain as a function of the nondimensional time for overmold samples at the $50{ }^{\circ} \mathrm{C} / 85 \% \mathrm{RH}$ condition. In most cases studied, the difference between experimental weight gain and predicted weight gain is less than 3\%. Belton et al. [5] states that the absorption and desorption processes are controlled by diffusion when the following three conditions are met. 


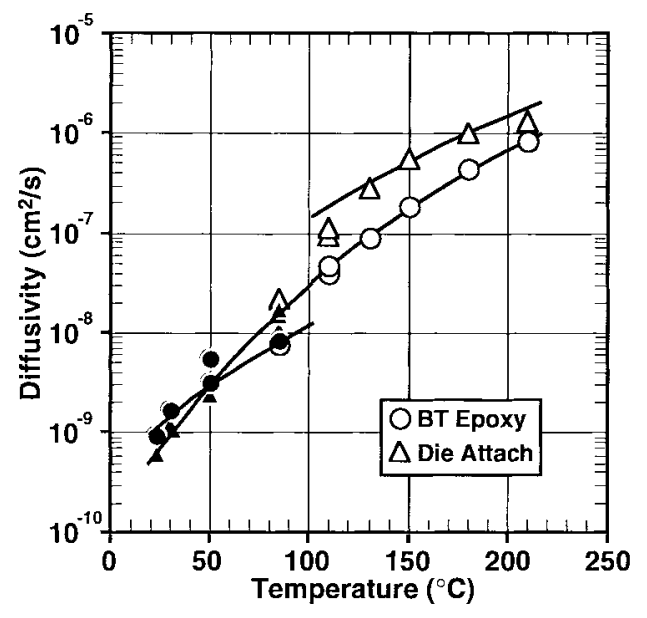

(a)

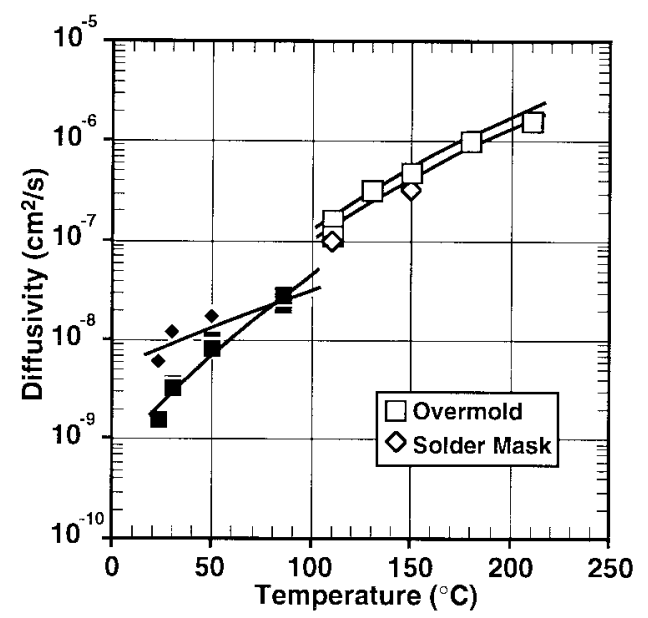

(b)

Fig. 3. Moisture absorption and desorption diffusivity as a function of temperature.

1) The weight gain curve appears linear at low nondimensional times.

2) The curve becomes concave downward at later times.

3) The weight gain versus nondimensional time for different thickness samples all collapse on a single curve.

All of the aforementioned conditions are met as shown in Fig. 2.

Fig. 3 shows the diffusivity dependency on temperature for BT epoxy, die attach, overmold, and solder mask. The Arrhenius equation, given by (3), is used to model the diffusivity

$$
\alpha=\alpha_{0} \exp \left(Q_{\alpha} / R T\right)
$$

where $T$ is the temperature $(\mathrm{K}), R$ is the Boltzmann constant ( $\left.R=8.63 \times 10^{-5} \mathrm{ev} / \mathrm{K}\right), \alpha_{o}$ is the diffusivity coefficient and $Q_{\alpha}$ is the activation energy. Numerical values for the diffusivity coefficient and activation energy are given in Table II.

If the moisture transport mechanism is controlled by diffusion, then the rate of absorption or desorption should accurately be predicted by the Arrhenius equation. The Arrhenius equation fits the experimental absorption data shown by solid symbols in Fig. 3, within $\pm 15 \%$ over the range of temperatures
TABLE II

AbSORPTION AND DESORPTION Diffusivity CONSTANTS FOR (3)

\begin{tabular}{|c|c|c|c|c|}
\hline \multirow[b]{2}{*}{ Material } & \multicolumn{2}{|c|}{ Absorption } & \multicolumn{2}{|c|}{ Desorption } \\
\hline & $\begin{array}{c}\alpha_{0} \\
\left(\mathrm{~cm}^{2} / \mathrm{s}\right) \\
\end{array}$ & $\begin{array}{c}\mathrm{Q}_{\alpha} \\
(\mathrm{ev} / \mathrm{K}) \\
\end{array}$ & $\begin{array}{c}\alpha_{\mathrm{o}} \\
\left(\mathrm{cm}^{2} / \mathrm{s}\right) \\
\end{array}$ & $\begin{array}{c}\mathrm{Q}_{\alpha} \\
(\mathrm{cv} / \mathrm{K}) \\
\end{array}$ \\
\hline $\begin{array}{c}\text { BT } \\
\text { Epoxy }\end{array}$ & $1.2 \times 10^{-4}$ & -0.295 & $6.0 \times 10^{-2}$ & -0.465 \\
\hline $\begin{array}{c}\text { Die } \\
\text { Attach }\end{array}$ & $7.0 \times 10^{-2}$ & -0.474 & $2.0 \times 10^{-2}$ & -0.392 \\
\hline $\begin{array}{l}\text { Over- } \\
\text { mold }\end{array}$ & $5.5 \times 10^{-3}$ & -0.376 & $1.1 \times 10^{-2}$ & -0.366 \\
\hline $\begin{array}{l}\text { Solder } \\
\text { Mask }\end{array}$ & $5.5 \times 10^{-6}$ & -0.167 & $2.7 \times 10^{-2}$ & -0.396 \\
\hline
\end{tabular}

considered. Experimental diffusivity data reported in this study compare within $30 \%$ to data found in the literature [6]-[9].

During absorption, water vapor condenses in internal micropores. During desorption, liquid water evaporates and is transported to the ambient. Because of these differences in the transport mechanisms, different constants are required to evaluate (3) for absorption and desorption.

\section{B. Saturation Concentration}

Saturation concentration data were measured to determine the maximum possible weight gain per sample volume for a particular ambient condition. The saturation concentration, $C_{\text {sat }}$, is a function of temperature, humidity, and material. When $C_{\text {sat }}$ is normalized by the ambient water vapor density, $\rho_{g}$, the concentration ratio, $\psi$, becomes a function of temperature and does not depend on the relative humidity. The concentration ratio dependency on temperature is modeled using the form of the Arrhenius equation given by

$$
\psi \equiv \frac{C_{\mathrm{sat}}}{\rho_{g}}=\psi_{\circ} \exp \left(Q_{\psi} / R T\right)
$$

The agreement between correlations based on (4) and experimental concentration ratio data is within $10 \%$ as shown in Fig. 4. Empirical constants used to model the concentration ratio dependency on temperature are given in Table III, where $T$ is measured in degrees Kelvin.

The physical state of moisture, either liquid or vapor, residing in PBGA materials may be inferred from the data shown in Fig. 4. Because the concentration of moisture, based on the volume of the sample, is several orders of magnitude greater than the ambient water vapor density at the same temperature, the majority of moisture residing in the package by mass must reside in the liquid state. This conclusion has enormous consequences when considering the moisture induced stresses during reflow. Vaporizing moisture from liquid deposits in micro-pores or along interfacial cracks provides a vapor reservoir from which high pressure steam is generated during reflow. 


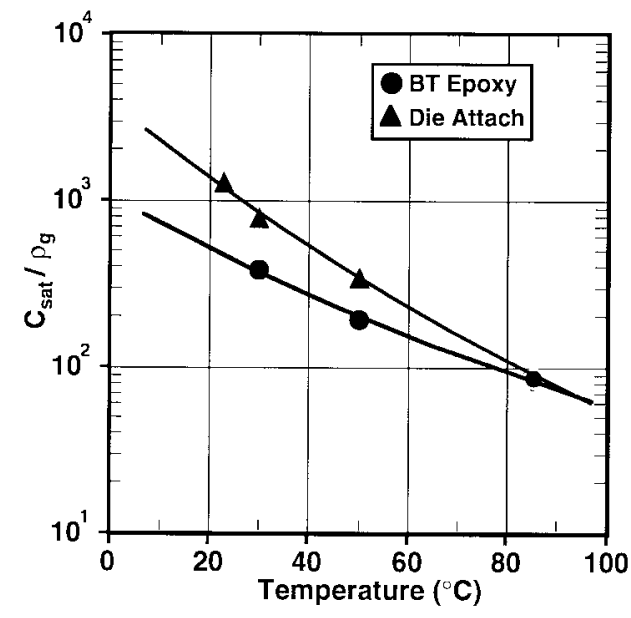

(a)

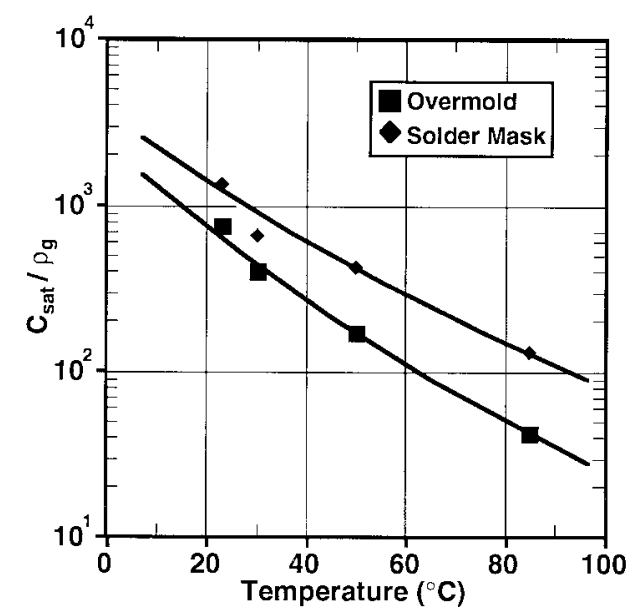

(b)

Fig. 4. Concentration ratio versus temperature.

\section{MOISTURE DifFUSION SimUlations}

PBGA packages can be designed more effectively if the moisture transport rate and local concentration, $C\left(\mathrm{~g} / \mathrm{cm}^{3}\right)$, are known. Traditionally, data are gathered using weight gain studies. However, erroneous conclusions may be reached because data gathered from weight gain measurements do not indicate whether significant amounts of moisture have reached the die attach region or if moisture resides predominately in the exterior packaging material. A 3-D FEA model is used to calculate the total moisture weight gain and to predict the moisture concentration in the die attach region.

\section{A. Change In Dependent Variable}

Transient moisture diffusion follows the same governing differential equation as the diffusion of heat, but the dependent variable, temperature, is replaced by moisture concentration and the thermal diffusivity is replaced by moisture diffusivity. Therefore, commercially available FEA software can be used to solve transient moisture diffusion problems. However, a unique problem arises in the diffusion of moisture. An interfacial concentration discontinuity results where two materials having different saturated concentrations are joined.
TABLE III

Concentration Ratio Constants for (4)

\begin{tabular}{c||c|c}
\hline Material & $\psi_{0}$ & $\mathrm{Q}_{\Psi}$ \\
$(-)$ & $(\mathrm{cv} / \mathrm{K})$ \\
\hline $\begin{array}{c}\text { BT } \\
\text { Epoxy }\end{array}$ & $2.1 \times 10^{-2}$ & 0.255 \\
\hline $\begin{array}{c}\text { Die } \\
\text { Allach }\end{array}$ & $4.8 \times 10^{-4}$ & 0.375 \\
\hline $\begin{array}{c}\text { Over- } \\
\text { mold }\end{array}$ & $9.8 \times 10^{-5}$ & 0.400 \\
\hline $\begin{array}{c}\text { Solder } \\
\text { Mask }\end{array}$ & $2.8 \times 10^{-3}$ & 0.332 \\
\hline
\end{tabular}

PBGA packages have several interfaces where the solubility of mating materials is different. For example, at equilibrium for the $23{ }^{\circ} \mathrm{C} / 70 \% \mathrm{RH}$ condition, the saturated concentration of moisture in BT epoxy is $0.0066 \mathrm{~g} / \mathrm{cm}^{3}$, whereas in the die attach it is $0.017 \mathrm{~g} / \mathrm{cm}^{3}$. Standard FEA software will not easily accommodate a step discontinuity at an interface.

The interfacial discontinuity can be removed by changing the dependent variable in (1) from concentration to partial pressure [10]. According to the Nernst partition rule [11], which is a statement of chemical equilibrium, the partial pressure must be constant across an interface. The partial pressure of moisture, $P(\mathrm{MPa})$, for a given material is defined in terms of its solubility, $\mathrm{Sg} / \mathrm{cm}^{3} / \mathrm{MPa}$ )

$$
P=\frac{C}{S}
$$

The solubility, like the concentration ratio, is a function of only temperature as given in (6), assuming ideal gas behavior

$$
S=2.17 \frac{\psi}{T}
$$

where $T$ is measured in degrees Kelvin and the concentration ratio, $\psi$, is given by (4).

The solubility has a physical interpretation as the slope of the concentration versus partial pressure. Fig. 5 shows the linear relation between concentration and partial pressure corresponding to $30 \%, 60 \%$, and $85 \%$ relative humidity at $30{ }^{\circ} \mathrm{C}$ and $85^{\circ} \mathrm{C}$. Solving (5) for $C$ and substituting into (1) yields the model equation for the FEA simulation given in

$$
\frac{\partial P_{v}^{2}}{\partial x^{2}}+\frac{\partial P_{v}^{2}}{\partial y^{2}}+\frac{\partial P_{v}^{2}}{\partial z^{2}}=\frac{1}{\alpha} \frac{\partial P_{v}}{\partial t} .
$$

\section{B. FEA Model Simulations}

Fig. 6 shows the geometry and dimensions of the $68 \mathrm{I} / \mathrm{O}$ PBGA package used for moisture simulations and solder pot dip tests. Realistic geometry effects, such as internal vias, metallization on the die pad, and metallization at the solder joint interconnects are included in the model.

Moisture absorption and desorption processes are modeled with a standard FEA code using a 3-D eight-noded transient diffusion element. Partial pressure boundary conditions are imposed on external nodes to match the ambient temperature and humidity conditions. A zero partial pressure initial condition is imposed for all interior nodes, because the package is 


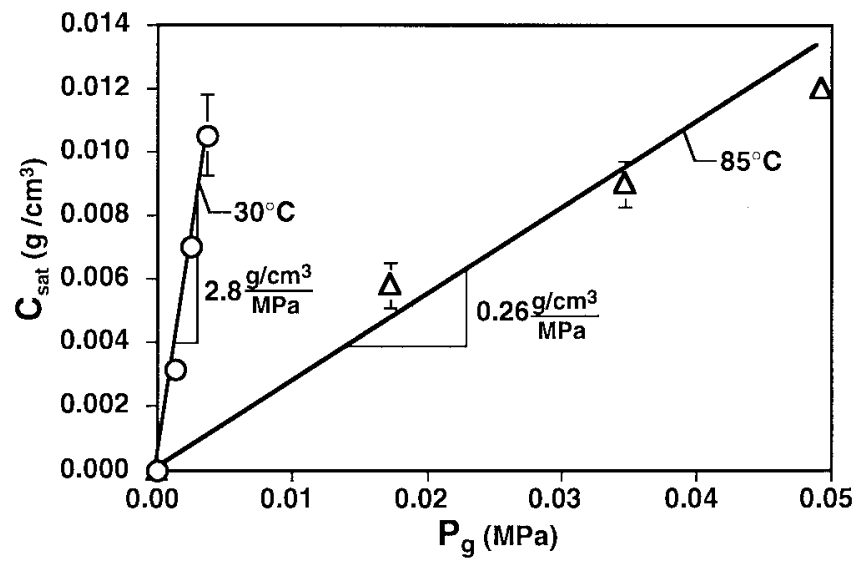

Fig. 5. Overmold saturated concentration as a function of ambient water vapor pressure.

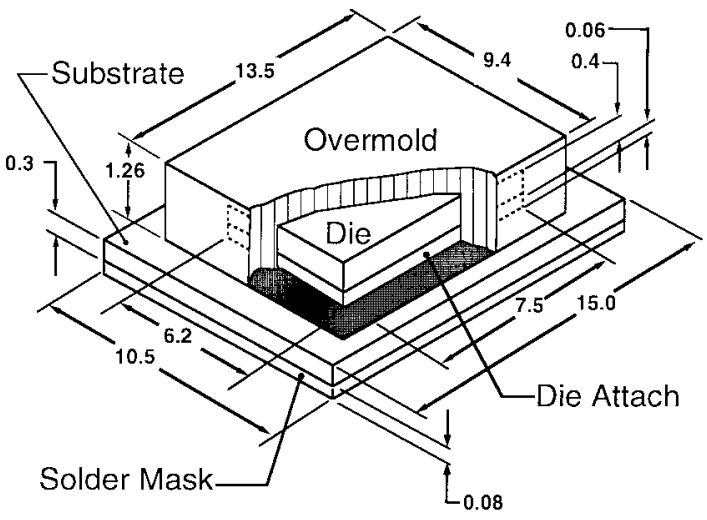

Fig. 6. PBGA geometry, dimensions (mm).

assumed to be $100 \%$ dry. The weight gain for each time step is calculated as a post process step. The FEA model predicts the partial pressure for each element from which the local concentration may be determined using (5). The volume and concentration is know for each element; thus, the mass of each element may be calculated. The total package weight gain is calculated by summing the individual mass contributions for each element for a given time step.

Transient weight gain predictions at the JEDEC Standard level 1 and level 3 conditions (i.e., $85{ }^{\circ} \mathrm{C} / 85 \% \mathrm{RH}$ and $30{ }^{\circ} \mathrm{C} / 60 \% \mathrm{RH}$, respectively) are compared to experimental data in Fig. 7. The agreement between data and simulations is within $10 \%$ for absorption as well as desorption processes. Although a more simplified one-dimensional analysis may be used to estimate the local concentration at any interface, a fully 3-D analysis is required to account for realistic packaging geometry such as internal metallization or vias.

\section{CRitical Moisture Concentration}

The critical moisture concentration leading to die delamination was determined by conducting popcorn tests on saturated $68 \mathrm{I} / \mathrm{O}$ PBGA using the solder dip test as reported in Hawkins et al. [6]. The test consists of mounting a package in a deflection gage with the sensor in contact with the substrate. The package and deflection gauge assembly are inserted into a

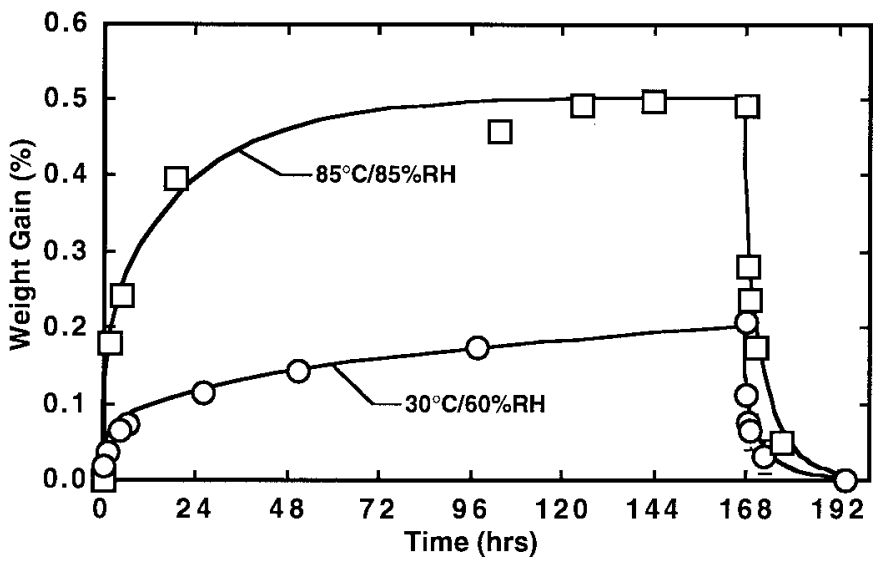

Fig. 7. Comparison of 68 I/O PBGA experimental weight gain and bake-out data to finite element analysis (FEA) simulations.

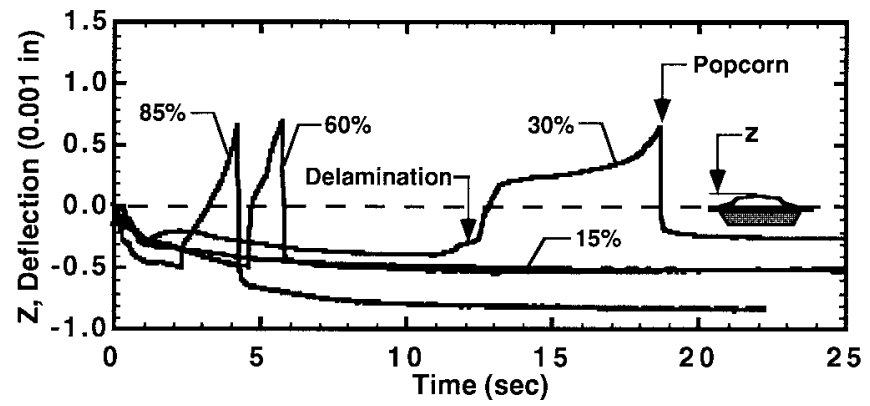

Fig. 8. 68 I/O package substrate deflection versus time during solder pot dip test.

solder pot at $230^{\circ} \mathrm{C}$ for at least 2 min while transient deflection measurements are recorded. Below a critical moisture level, the die-die attach interface does not delaminate because the adhesion of the die attach is able to support the local stress state induced by high pressure steam and thermo-mechanical induced stresses.

Fig. 8 shows the substrate deflection as a function of time during a solder pot dip test. Delamination was detected by a sudden upward bowing of the substrate. It is well known that the adhesion strength decreases with increasing moisture concentration (Getkin and Bar-Cohen [12]). As a consequence, packages soaked at higher humidity ratios delaminated sooner in response to the thermo-mechanical induced stresses. A popcorn failure results when the package cracks, relieving high pressure steam, and was detected by a sudden drop in the substrate deflection following delamination. Popcorn failures were detected for packages saturated at the $85{ }^{\circ} \mathrm{C} / 85 \% \mathrm{RH}$, $85^{\circ} \mathrm{C} / 60 \% \mathrm{RH}$, and $85^{\circ} \mathrm{C} / 30 \% \mathrm{RH}$ conditions, while packages saturated at $85{ }^{\circ} \mathrm{C} / 15 \% \mathrm{RH}$ did not delaminate. A greater time delay was required to popcorn packages once delaminated at the $85{ }^{\circ} \mathrm{C} / 30 \% \mathrm{RH}$ condition because insufficient moisture was available directly at the die-die attach interface and had to be transported from the interior regions of the die attach to support the growth of the bowing substrate. For example, as shown in Fig. 8 , at $85{ }^{\circ} \mathrm{C} / 85 \% \mathrm{RH}, 3 \mathrm{~s}$ were required to popcorn after delamination whereas at $85^{\circ} \mathrm{C} / 30 \% \mathrm{RH}, 7 \mathrm{~s}$ were required. There appears to be a critical die attach moisture concentration that, if exceeded, promotes die delamination 
followed by a popcorn failure. For the 68 I/O PBGA package considered in this study, as shown in Fig. 6, the critical die attach concentration appears to be between $0.0048 \mathrm{~g} / \mathrm{cm}^{3}$ and $0.0095 \mathrm{~g} / \mathrm{cm}^{3}$ corresponding to the $85{ }^{\circ} \mathrm{C} / 15 \% \mathrm{RH}$ and $85{ }^{\circ} \mathrm{C} / 30 \% \mathrm{RH}$ condition, respectively.

In addition to moisture concentration, several other factors affect whether a PBGA package will popcorn. A partial list includes die adhesion, substrate adhesion to overmold, stiffness of substrate, overmold and substrate fracture toughness, and the reflow profile. A fully integrated popcorn model needs to include these effects as well as a transient moisture transport simulation.

Several concepts have been proposed in the literature to reduce popcorn failures in PBGA packages during reflow. The vent hole concept, (Freyman et al. [13]), relieves high pressure steam through a small hole extending through the substrate into the die attach. Vent hole packages recently tested passed the $85{ }^{\circ} \mathrm{C} / 85 \% \mathrm{RH}$ condition using the $230{ }^{\circ} \mathrm{C}$ solder dip test. Inoue et al. [14] showed that improved surface cleaning processes will improve the popcorn performance.

\section{CONCLUSION}

Temperature dependent diffusivity and concentration ratio data for BT Epoxy, die attach, overmold, and solder mask materials are correlated with the Arrhenius equation. A method is presented for predicting the transient moisture diffusion rates through a multimaterial package. A FEA model accurately predicts the weight gain and bake-out for a PBGA package. A critical die attach moisture concentration exists that, if exceeded, promotes a popcorn failure.

\section{ACKNOWLEDGMENT}

The authors wish to express their appreciation to B. Mullen and G. Urbish for their support during the course of this project and J. Flaugher and D. Vonderstrasse for preparing material samples and detecting popcorn failures.

\section{REFERENCES}

[1] JEDEC Standard, Test Method A112, "Moisture-induced stress sensitivity for plastic surface mount devices," Electronic Industries Association, 1994.

[2] B. Poborets, Q. S. M. Ilyas, M. Potter, and J. Argyle, "Reliability and moisture sensitivity evaluation of 225-pin, 2 layered overmolded (OMPAC) ball grid array package," in Proc. 45th Electron. Comp. Technol. Conf., Las Vegas, NV, May 21-24, 1995, pp. 434-439.

[3] G. S. Ganesan and H. M. Berg, "Model and analyses for solder reflow cracking phenomenon in SMT plastic packages," IEEE Trans. Comp., Hybrids, Manufact. Technol., vol. 16, pp. 940-948, 1993.

[4] B. Gebhart, Heat Conduction and Mass Diffusion. New York: McGraw Hill, 1993, pp. 287.
[5] D. J. Belton, E. A. Sullivan, and M. J. Molter, "Moisture sorption and its effects upon the microstructure of epoxy molding compounds," in Proc. 3rd Int. Electron. Manufact. Technol. Symp., 1987, pp. 158-169.

[6] G. Hawkins, G. Ganesan, G. Lewis, and H. Berg, "The PBGA: A systematic study of moisture resistance," in Proc. IEPS Conf., 1994, pp. 588-602.

[7] M. Kitano, A. Nishimura, and S. Kawai, "Analysis of packaging cracking during reflow soldering process," in Proc. IEEE Int. Reliab. Phys. Symp., 1988, pp. 90-95.

[8] R. L. Shook, T. R. Conrad, V. S. Sastry, and D. B. Steele, "Diffusion model to derate moisture sensitive surface mount IC's for factory use conditions," in Proc. 45th Electron. Comp., Technol. Conf., Las Vegas, NV, May 21-24, 1995, pp. 440-449.

[9] EIAJ, ED-4701, "Environmental and endurance test methods for semiconductor devices," Electronic Industries Association of Japan, 1992.

[10] G. Ganesan, Private communication, Motorola, SPS Division, Phoenix, AZ, 1995.

[11] W. Jost, Diffusion in Solids, Liquid, Gases. New York: Academic, 1952, p. 25.

[12] V. Gektin and A. Bar-Cohen, "Mechanistic figures of merit for die-attach materials," in Proc. ITHERM V, InterSoc. Conf. Thermal Phenomena Electron. Syst., Orlando, FL, 1996, pp. 306-313.

[13] B. J. Freyman, F. J. Juskey, and B. M. Miles, "Moisture relief for chip carrier," U.S. Patent 5296738 , Mar. 22, 1994.

[14] Y. Inoue, K. Sawada, N. Kawamura, and T. Sudo, "A synthetic criterion for Level-1 crack-free package-proposal of a superior package structure," in Proc. Electron. Comp. Technol. Conf., 1996, pp. 71-77.

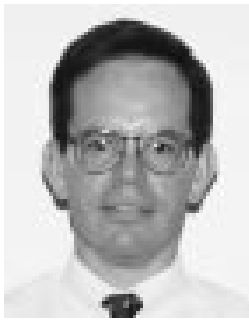

Jesse E. Galloway received the Ph.D. degree in mechanical engineering from Purdue University, West Lafayette, IN.

$\mathrm{He}$ is a Lead Mechanical Engineer in the Manufacturing Processes Laboratory, Advanced Manufacturing Technology Center, Motorola's Land Mobile Products Sector, Plantation, FL. He joined Motorola in 1993 and is responsible for performing thermal and mechanical analyses and experiments on board level assemblies. He also is responsible for conducting manufacturing process simulations. He has written numerous papers in the area of high power electronic cooling.

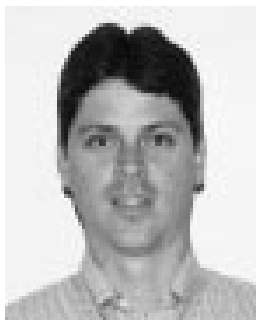

Barry M. Miles received the B.S. degree in chemical engineering from the University of South Florida, Tampa.

$\mathrm{He}$ is a Senior Staff Engineer and Manager of the Advanced Manufacturing Technology Center IC Packaging Lab, Motorola's Land Mobile Products Sector, Plantation, FL. He is responsible for semiconductor package development and the implementation of these packages into the manufacturing environment, specific to portable and mobile electronic communications products. He was one of the original members of the PBGA package development team at Motorola, Plantation, with responsibility for package level reliability testing and moisture sensitivity studies. Employed by Motorola since 1983, he has also done work in the areas of thin film hybrids, flex and printed circuit board fabrication, and surface mount assembly. He has written numerous papers for publication in technical conference proceedings and has co-authored a chapter on PBGA assembly practices in Ball Grid Array Technology. He has 12 issued U.S. patents. 